\title{
Understanding neurodegenerative changes of the afferent visual pathway in MS
}

Hanna G. Zimmermann, PhD, and Frederike Cosima Oertel, MD

Neurol Neuroimmunol Neuroinflamm 2020;7:e667. doi:10.1212/NXI.0000000000000667

The chronic involvement of the afferent visual system in multiple sclerosis (MS) is a powerful model to understand the temporal course and functional relevance of neurodegeneration because it is very well distinguishable from neighboring structures and offers quantifiable structural and functional metrics. Optical coherence tomography (OCT) of the retina and diffusion tensor imaging (DTI)-based tractography of the optic radiation have proven to provide sensitive markers for neurodegeneration of the visual pathway in MS. ${ }^{1,2}$ OCT-derived neuroaxonal retinal damage, represented by thinning of the retinal nerve fiber layer (RNFL) and ganglion cell/inner plexiform layer (GCIPL), has been reported in patients with MS with a history of optic neuritis $(\mathrm{ON})$ and - to a lesser extent-also independent of ON episodes. ${ }^{1}$ RNFL and GCIPL show strong associations with visual function in MS, especially with lowcontrast visual acuity. ${ }^{3}$ Both layer thicknesses are associated with brain atrophy: this association being stronger in the eyes without a history of $\mathrm{ON}^{3}$

DTI facilitates the reconstruction and analysis of white matter tracts and can thereby reveal microstructural changes of the optic radiation as the most frequently affected white matter pathway in MS. ${ }^{2}$ Although fractional anisotropy (FA) is considered as a marker of microstructural integrity, higher radial diffusivity $(\mathrm{RD})$ can be caused by demyelination and axial diffusivity $(\mathrm{AD})$ changes are suggested to be associated with axonal damage. ${ }^{2}$

In this issue of Neurology ${ }^{\circledR}$ Neuroimmunology \& Neuroinflammation, Pawlitzki et al. ${ }^{4}$ describe retinal neuroaxonal loss and microstructural changes in the optic radiation in MS, using OCT and DTI-based tractography. In this cross-sectional study, 17 patients with a history of a single unilateral ON episode and a sex- and age-matched cohort of 11 patients without an ON episode were included. Pawlitzki et al. found more retinal atrophy and microstructural damage of the optic radiation in patients with a history of ON-measured by thinning of the RNFL and GCIPL as well as FA, $\mathrm{AD}$, and $\mathrm{RD}$ changes in the optic radiation. This clearly describes the pronounced damage in the visual system after a single ON episode. Furthermore, by reporting associations of RNFL and GCIPL thickness with DTI parameters, the study is an important confirmation of long-term anterograde and retrograde neuroaxonal loss in the afferent visual system. Interestingly, the thickness of the primary visual cortex was neither associated with optic radiation DTI parameters nor with RNFL and GCIPL thinning. ${ }^{4}$

DTI and retinal atrophy have emerged as important outcome measures in clinical MS research. ${ }^{1}$ However, to widely implement OCT and DTI for the individual monitoring of disease progression and treatment response, we still lack important pathologic and technical considerations.

The great advantages of OCT parameters include the rigorous and uniform quality control criteria, the reproducible correlation with visual function, and the measurability of even small degrees of atrophy. ${ }^{1,5}$ However, there is evidence that the test-retest reliability is associated with scan protocols, scan quality, rater bias, or physiologic variation of common OCT parameters ${ }^{6,7}$ while keeping in mind that OCT is not histopathology. Dead and nonfunctional ganglion cells

\author{
Correspondence \\ Dr. Zimmermann \\ hanna.zimmermann@charite.de
}

RELATED ARTICLE

Article

MS optic neuritis-induced

long-term structural

changes within the visual

pathway

Page e665 
might also have a volume effect; meanwhile, other cells such as astrocytes could contribute to thickness measurements. There is evidence that edema-associated with chronic inflammation-occurs in the RNFL, one of the most common OCT outcome parameters. ${ }^{8}$ Thus, the effect of pseudoatrophy, as we know it from MRI-based brain volume measurements, might also be present in the RNFL.

The same applies to DTI-based metrics. ${ }^{2}$ In contrast to OCT, the protocols for DTI acquisition and postprocessing are still very heterogeneous, which substantially limits the use of DTI as a potential biomarker. ${ }^{2,9}$ Furthermore, the diffusion tensors in the optic radiation are influenced by optic radiation lesions and (Wallerian) neurodegeneration resulting from optic nerve damage. ${ }^{2}$ So far, researchers have not succeeded in untangling these effects. In addition, the study of Pawlitzki et al. ${ }^{4}$ does not shed light on this enigma: the frequency of lesions in the optic radiation is lower in the non-ON group, and the extent of $\mathrm{ON}$-independent visual pathway damage in this cohort could not be evaluated because the study did not include healthy controls.

The lack of normal reference values, confounded with the wide range of physiologic variation, challenge the interpretation of imaging markers and, thus, their application for individualized monitoring in MS. In the future, improving OCT- and DTI-based metrics and combining their application with newer methods such as the volumetric analyses of the lateral geniculate nucleus will implement a gapless assessment of structure and function in the afferent visual system and thereby new pathophysiologic insights. ${ }^{10}$ For example, it is currently controversially discussed whether ONindependent retinal atrophy in MS is a result of subclinical ON episodes, ongoing widespread inflammation and demyelination, trans-synaptic retrograde neurodegeneration from lesions in the white matter pathway or a primary retinal degeneration. None of these hypotheses is mutually exclusive, and each of these may partially contribute to our observation. Closing the gap between these metrics by applying ongoing methodical advancements of afferent visual system research in longitudinal studies will expand our pathophysiologic understanding and the differentiation of normal and diseaserelated neurodegeneration in the afferent visual system of patients with MS.

\section{Study funding}

No targeted funding reported.

\section{Disclosure}

H.G.Z. reports research grants from Novartis, unrelated to this study. F.C.O. was employed by Nocturne, unrelated to this study. Go to Neurology.org/NN for full disclosures.

\section{References}

1. Petzold A, Balcer LJ, Calabresi PA, et al. Retinal layer segmentation in multiple sclerosis: a systematic review and meta-analysis. Lancet Neurol 2017;16:797-812.

2. Kuchling J, Brandt AU, Paul F, Scheel M. Diffusion tensor imaging for multilevel assessment of the visual pathway: possibilities for personalized outcome prediction in autoimmune disorders of the central nervous system. EPMA J 2017;8:279-294.

3. Oertel FC, Zimmermann HG, Brandt AU, Paul F. Novel uses of retinal imaging with optical coherence tomography in multiple sclerosis. Expert Rev Neurother 2019;19: 31-43.

4. Pawlitzki M, Horbruegger M, Loewe K, et al. MS optic neuritis-induced long-term structural changes within the visual pathway. Neurol Neuroimmunol Neuroinflamm 2020; 7:e665. doi: 10.1212/NXI.0000000000000665.

5. Tewarie P, Balk L, Costello F, et al. The OSCAR-IB consensus criteria for retinal OCT quality assessment. PLoS One 2012;7:e34823.

6. Oberwahrenbrock T, Weinhold M, Mikolajczak J, et al. Reliability of intra-retinal layer thickness estimates. PLoS One 2015;10:e137316.

7. Oberwahrenbrock T, Traber GL, Lukas S, et al. Multicenter reliability of semiautomatic retinal layer segmentation using OCT. Neurol Neuroimmunol Neuroinflamm 2018;5:e449. doi: 10.1212/NXI.0000000000000449.

8. Oertel FC, Outteryck O, Knier B, et al. Optical coherence tomography in myelinoligodendrocyte-glycoprotein antibody-seropositive patients: a longitudinal study. J Neuroinflammation 2019;16:154.

9. Kuchling J, Backner Y, Oertel FC, et al. Comparison of probabilistic tractography and tract-based spatial statistics for assessing optic radiation damage in patients with autoimmune inflammatory disorders of the central nervous system. Neuroimage Clin 2018;19:538-550.

10. Papadopoulou A, Gaetano L, Pfister A, et al. Damage of the lateral geniculate nucleus in MS: assessing the missing node of the visual pathway. Neurology 2019;92: e2240-e2249. 


\title{
Neurology $^{\odot}$ \\ Neuroimmunology \& Neuroinflammation
}

\author{
Understanding neurodegenerative changes of the afferent visual pathway in MS \\ Hanna G. Zimmermann and Frederike Cosima Oertel \\ Neurol Neuroimmunol Neuroinflamm 2020;7; \\ DOI 10.1212/NXI.0000000000000667
}

This information is current as of January 22, 2020

\section{Updated Information \& Services \\ References \\ Subspecialty Collections}

Permissions \& Licensing

Reprints including high resolution figures, can be found at: http://nn.neurology.org/content/7/2/e667.full.html

This article cites 10 articles, 2 of which you can access for free at: http://nn.neurology.org/content/7/2/e667.full.html\#\#ref-list-1

This article, along with others on similar topics, appears in the following collection(s):

DWI

http://nn.neurology.org//cgi/collection/dwi

Evoked Potentials/Visual

http://nn.neurology.org//cgi/collection/evoked_potentials-visual

MRI

http://nn.neurology.org//cgi/collection/mri

Multiple sclerosis

http://nn.neurology.org//cgi/collection/multiple_sclerosis

Optic neuritis; see Neuro-ophthalmology/Optic Nerve

http://nn.neurology.org//cgi/collection/optic_neuritis

Information about reproducing this article in parts (figures,tables) or in its entirety can be found online at:

http://nn.neurology.org/misc/about.xhtml\#permissions

Information about ordering reprints can be found online:

http://nn.neurology.org/misc/addir.xhtml\#reprintsus

Neurol Neuroimmunol Neuroinflamm is an official journal of the American Academy of Neurology.

Published since April 2014, it is an open-access, online-only, continuous publication journal. Copyright

Copyright $\odot 2020$ The Author(s). Published by Wolters Kluwer Health, Inc. on behalf of the American

Academy of Neurology.. All rights reserved. Online ISSN: 2332-7812.

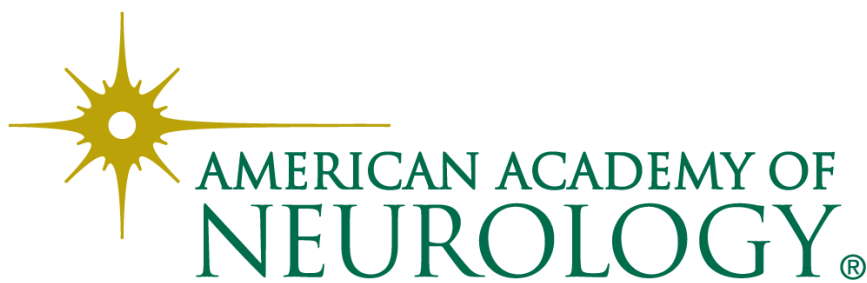

